\title{
On the Reform Strategy of Microbiology Teaching Model
}

\author{
Chen Yan*, Yang Zuisu, Qu Youle, Ding Guofang \\ School of Food and Medicine \\ Zhejiang Ocean University \\ Zhoushan 316022, China \\ Corresponding author: cyan@tju.edu.cn
}

\begin{abstract}
Explore the new teaching model of Microbiology, enhance the teaching quality and ultimately cultivate applied talents of biopharmaceutical major. Track the progress of frontier scientific research to optimize teaching contents, expand opening experiments to improve experimental teaching, and strengthen and innovate practice and internship in combination with school running and major characteristics. Through the indepth cooperation between theoretical and practical teaching, this course has become more professional, practical and cuttingedge. That has greatly enhanced students' enthusiasm and subjective initiative in learning, cultivated their logical thinking and practical abilities, and improved their ability in scientific exploration and professional quality, thus laying a solid foundation for cultivating their comprehensive professional quality.
\end{abstract}

Keywords-Microbiology; Biopharmacy; Teaching Reform; Teaching Practice

\section{INTRODUCTION}

It is explicitly stated in The Outline of China's 13th Fiveyear Development Plan that a new system for biological medicine should be built and innovative, ocean-based drugs should be developed to vigorously support the sustainable innovation of biotech drugs. Since 2017, the Ministry of Education has been actively promoting the construction of new engineering. Therefore, the biopharmacy major, one of the nine "new engineering" majors, enjoys good prospects for development.

Microbiology is a professional basic course of biopharmaceutical major and a compulsory course guiding professional core one such as fermentation engineering and biopharmaceutical technology. So it plays an important role in the course system of biopharmacy[1]. Whether students can firmly grasp Microbiology will directly influence their learning of core courses of the major. The course is a science studying microorganisms and the laws governing their life activities. That means it is a science which studies the forms and structures, nutrition and metabolism, growth and breeding of microorganisms under certain conditions and laws such as their heredity, classification and ecology and their application. Its task is to fully exploit, utilize and improve beneficial microorganisms, to control and transform harmful ones, and to serve health and medicine of human society and other businesses through the systematic learning of microbiological

This work was financially supported by Zhejiang Provincial Natural Science Foundation No. LQ18B060004 knowledge[2]. In recent years, with the rapid development of systems and synthetic biology, human beings have evolved from discovering living things to being able to create them and realize bio-manufacturing by using them. Judging from talent training of this major, the theoretical system of Microbiology's curriculum knowledge needs constant updates and developments. Meanwhile, the subject's demand for the operating skills in its experimental courses is increasingly higher[3]. Owing to contradictions between the evolving, strong knowledge system of the course and relatively less class time after the reform of university teaching system, and between experimental teaching of the course and contents of theory teaching, students fail to absorb enough knowledge during course learning and teaching effect is undesirable, which puts forward higher demand for the teaching of the course. In order to improve the teaching quality and meet the subject's goal of training applied talents, this paper gives some thought and preliminary discussion on reform in terms of teaching contents, experimental teaching and practice and internship.

\section{Optimizing TEAching Content AND ENHANCING CLASSROOM INTERACTION}

Microbiology is a basic course in biological science and engineering with its traditional teaching content being general Microbiology. It mainly consists of parts such as taxonomy, forms and structures, nutrition and metabolism, growth and control, heredity and biology of microorganisms. In recent years, with the burgeoning of modern biotechnology, especially technologies like systems and synthetic biotechnology, human understanding of microorganisms is changing with each passing day and knowledge system is updating rapidly. As a result, the theoretical system of the course should also keep pace with the time. It ought to pay attention to the updating of teaching contents and at the same time, give a general introduction to the typical cases of the application of microorganisms in biopharmaceutical engineering in terms of the major characteristics and demands of biopharmacy. For instance, the historic breakthrough[4,5] that major drugs like artemisinin and taxadiene have made in microbial metabolism engineering and synthetic biotechnology can be introduced to enrich teaching contents.

Based on the systematic knowledge of Microbiology, the course strives to reflect the new achievements of microbial 
technology and to formulate the syllabus of germ theory curriculum. This course is divided into two parts, namely, basis of Microbiology and progress of frontier research on microorganism. The first part includes the forms and structures, nutrition and metabolism, growth and control, heredity and breeding of microorganism and other basic knowledge. It emphasizes on the metabolism and growth of microorganism so that students can understand important contents such as the central pathway of carbon metabolism, fermentation and respiration, growth and metabolism regulation. Thus they can have a basic knowledge of complex networks of biodiversity metabolism like primary and secondary metabolism of microorganism and growth control, as well as its close relationship with human's production and life. On that basis, the progress of frontier research of this subject will be introduced as the second part of this course, tracking and introducing the historic breakthrough which the application of microbial metabolism and growth control have made in microbiological pharmacy. Therefore, students can comprehend microorganism is of vital importance to microbiological pharmacy, can learn the frontier progress and development in this field and can know about the research methods and techniques needed by the research of this field. Stressing the cultivation of student's independent thinking in it, the course is designed to make them fully understand the development of the subject, able to have preliminary thoughts and develop interest in research by introducing the progress of the frontier research of microbiological pharmacy.

With multiple knowledge points in the course and close connections between them, various teaching methods are supposed to be used flexibly in the teaching process to enhance interaction with students and fully mobilize their enthusiasm, thus strengthening the teaching effect. For example, more pictures can be presented in place of text output as teaching aid and life-based languages can be used properly in place of the stiff, abstract jargon on the textbooks in courseware making. Thus students will be able to absorb knowledge on the books in a vivid, visualized and profound way. On the basis of lecturing, an increase in teaching methods like independent group study before class and group report and discussion in class will boost students' engagement and learning passion and can cultivate them to study and think independently as expected. Meanwhile, teachers should track and learn the news about the academic development of this major in time such as the biomanufacturing of major drugs like terpenoids, alkaloid and poly ketone. They should also integrate the latest research results, hot spots and key technologies to be solved in this field into the teaching contents moderately and adopt heuristic teaching to make students more interested in learning and know more about their major. Thus their logical thinking can be developed and creativity can be stimulated.

\section{IMPROVIng EXPERIMENTAL TEACHING AND CULtivating RESEARCH QUALITY}

The technology of microbiological experimental operation underpins the research on biopharmaceutical technology, the former playing a significant role in key processes such as the development and production expansion of new drugs. In undergraduate teaching, the experimental teaching of
Microbiology is one of the important ways and key links to cultivate the professional skills and research quality of students major in biopharmacy. Nevertheless, there are relatively few teaching hours for experimental teaching of Microbiology in this major at present. What's worse, as biotechnology is progressing day by day, the contents of experimental teaching remain restricted to dated operations like simple observation of cell forms via microscopes and plate colony counting. Such experimental curriculum is not conducive to the objective of biopharmacy major to cultivate applied talents. Hence this course have made appropriate adjustments for the curriculum and teaching contents of the experimental course to achieve its close integration with teaching contents and the coordination between practical and theoretical courses.

In order to give full play to students' subjective initiative, the experimental course of Microbiology is designed to reduce replication experiments and increase the comprehensive and exploratory experiments accordingly[6]. For instance, teachers can first set up simple replication experiments like observing forms of different microbial cells and measuring growth curves, and then gradually set up comprehensive ones like extracting the target microorganism from the mixed culture of Bacillus, Coccus and Saccharomycetes, and finally upgrade to exploratory and heuristic ones like screening the active microorganism of the target organism from sea water and pureculturing it. Teachers should train students to discover, analyze and solve problems by the comprehensive application of according microbiological theories to enhance their thinking initiative and experimental enthusiasm, thus improving the quality of microorganism experimental teaching.

In practical courses in short terms, a huge experiment open to scientific exploration will be designed based on major characteristics and project research. 4-6 students will make a group and interesting experimental projects will be set up. Students will be allowed to innovate and design experiments on their own according to what they will have learned. Then they'll record procedures and results of experiments, analyses and discussion in their lab reports. Finally they'll give concluding reports via PPT presentation and fully discuss theories, process and results of their experiments. Students can truly experience research experiments via such experimental teaching of integral process. The combination of team work and professional knowledge they've learned will get them honed in logical thinking and manipulative ability and more enthusiastic in research exploration as well.

\section{InNOVATING PRACTICE AND INTERNSHIP AND ENHANCING COMPREHENSIVE ABILITIES}

The biopharmaceutical major lays its emphasis on the combination of production, study and research and requires teachers to pay high attention to cultivating students' practical ability. In the course teaching of Microbiology, the cultivation of their extracurricular practical ability should also be paid attention to. Microorganisms are closely related to human life. Similarly, there are also countless microorganisms living in the air, water and other environments on which human beings depend. Located in Zhoushan, an island city, Zhejiang Ocean University faces the East China Sea and is surrounded by rolling hills. Its geographic location, a unique advantage, 
provides an enabling environment for the research of environmental microorganisms like ocean and soil. In order to inspect students' actual grasp and application of knowledge after learning basic theories and experimental knowledge of Microbiology, they will be arranged for field practice. Or they will be organized to collect microorganism samples in Shanghai according to ocean-related majors of the university. The third choice is sampling on mountains, observation, classification and determination of microorganisms' forms, separation and screening of strains which produce natural active substance and their pure culture. In the field practice, key theories such as the forms, screening and cultivation, classification and determination of microorganisms will be consolidated and the potential of environmental microorganisms for applications and their research orientations will be discussed. As students are taught through lively learning atmosphere, their enthusiasm for learning is generally upsurging, which can not only train their practical abilities but also broaden their professional horizons in practice.

Additionally, internship in enterprise is an effective way for students to gain an in-depth understanding of professional knowledge and to get in touch with the industry dynamics. There are a couple of biopharmaceutical enterprises in Zhejiang. Presently, the university has established good relationships with such enterprises like Zhejiang Hailisheng Biotechnology Co., Ltd. and Zhejiang Haizheng Pharmaceutical Co., Ltd. to cooperate with them by production, study and research. When students are visiting the enterprises, technicians will be arranged to explain knowledge such as the breeding, fermentation culture and process control of the strains used in drug production, as well as product extraction, which will make students grasp professional knowledge in internship. Meanwhile, practical operation training will be arranged appropriately so that students, under the guidance of professional technicians, can practice relevant unit operation in the actual process. Eventually technicians will remark on each student's operation and give advice, criticism and encouragement. The firsthand experience of microorganism technology will help students establish a professional knowledge system to truly apply what they’ve learned.

\section{CONCLUSION}

With the rapid development of biological science and technology, the biopharmaceutical major for undergraduate attaches increasing importance to and puts forward higher requirements for the teaching of Microbiology. Via some teaching experience accumulated in the teaching of Microbiology, this paper makes a preliminary exploration on the reform of this course from three aspects, namely, teaching contents, experimental teaching and practice and internship. Teachers should communicate and interact with students more in teaching, discover and improve the deficiencies in the courses in time and improve their own teaching levels and professional quality constantly. They also ought to give full guidance and support in professional projects like the undergraduate competition and make efforts to cultivate professional talents in biopharmacy with solid knowledge and skills.

\section{REFERENCES}

[1] Shen Ping, Chen Xiangdong. Microbiology 8th. Ed)[M]. Beijing:Higher Education Press, 2016.1.

[2] Zhou Deqing. Microbiology Course (3th. Ed)[M]. Beijing:Higher Education Press, 2011.4.

[3] Li Hui, Li Heng,Geng Yan Dou Wenfang,Shi Jinsong, Xu Zhengsong.Teaching reform and practice of Microbiology in biopharmaceutical engineering [J]. Guang zhou Chemical Industry, 2012, 40(7):179-181.

[4] Ajikumar P.K., Xiao W.H., Tyo K.E.J., et al. Isoprenoid pathway optimization for taxol precu.rsor overproduction in Escherichia coli[J]. Science, 2010, 330(6000): 70.

[5] Paddon C.J., Westfall P.J., Pitera D.J., et al. High-level semi-synthetic production of the potent antimalarial artemisinin[J]. Nature, 2013, 496(7446): 528.

[6] Wu Fangli,Reform and practice of Microbiology experiment teaching in pharmaceutical engineering [J]. The Guide of Science \& Education, 2013 (16):137-138 